\title{
Knowledge Management Systems
}

\section{Reports from the Field: Knowledge and Learning Applications in Practice}

\author{
Dr. Julee Hafner, Chair \\ The Chicago School Of Professional Psychology \\ jhhrsearch@gmail.com
}

\author{
Dr. Alexander Kaiser, Co-Chair \\ Vienna University of Economics and Business \\ alexander.kaiser@wu.ac.at
}

\begin{abstract}
Welcome to this, the 54th Hawaii International Conference on System Sciences (HICSS) conference. This Reports from the Field Minitrack, under the Knowledge Innovation and Entrepreneurial Systems Track, proudly brings you the latest research focused on the application of innovation of knowledge management issues as reported by both researchers and practitioners alike. With the focus on application, this minitrack helps practioners and theorists alike. It is here we examine how theory informs and impacts practice as well as how practice can influence theory from the practioner perspective.
\end{abstract}

\section{Introduction}

How do our theories on knowledge management and organizational learning contribute to real-world applications? Although there are many journals that focus on KM topics in systems-oriented research, theory development is at risk of becoming isolated from practical application. The needs and experiences of knowledge workers, who develop, implement, manage, and use knowledge management systems are at risk. It is within this divide between the knowledge systems research being conducted, and the needs and experiences of these knowledge workers that this minitrack is focused.

These practitioners in the field can provide invaluable insight to the research community in terms of practical application skills. It is important to be aware that there are countless practical perspectives on how to initiate, coordinate and monitor organizational learning processes.
The goal of this minitrack is to provide this "bridge" between the knowledge management and organizational learning academic scholars that build theory and the systems practitioner community. This mini-track encourages a focus upon how theory informs and impacts practice as well as how practice can influence theory.

In Reports From The Field, we are devoted to providing new research avenue to conduct research for building theory while improving the application of results to knowledge management systems in the practitioner community. It is hoped that accepted submissions will document specific knowledge system successes and failures within organizations from a practitioner perspective. For this session the following two papers were accepted and can be downloaded for your review.

\section{Nina Helander, Annamaija Paunu, and Pasi Hellsten}

Our first presenters are, Nina Helander, Annamaija Paunu, and Pasi Hellsten who will present their paper entitled: "Knowledge management processes in practice: Empirical insights from the public sector".

As the field of knowledge management continues to grow, KM processes are beginning to assist all organizations in a variety of functions. Public sector organizations, are now looking to the use of a KM process model, similar to their private sector counterparts providing the value in problem solving, decision making, and strategic planning at various stages. The integration of technology, driven by the use 
of specific processes that enable organizations to achieve their goals also has been increasing. Previous study of public sector knowledge management has focused on issues related to knowledge sharing, information systems, and data quality issues.

This empirical study comprised five public sector cases selected to represent the different stages of the knowledge process phases in public sector organizations from Finland. The types of challenges and enabling factors at different stages of the knowledge management process model were used to understand public sector operations and determine different perspectives on knowledge management issues.

The following submission aims to view the whole process of knowledge processing in the public sector. Identification of enabling factors used in a successful knowledge management process as well as the inherent challenges unique to public section organizations are discussed.

\section{Alexander Kaiser, Lisa-Maria Baumgartner, Anna Grill, and Sebastian Neumaier}

For our final submission, four authors will present their submission, "An advanced knowledge-based analysis of company vision statements".

The creation of a shared organizational vision can assist organizations in creating knowledge-based vision development practices and processes to understand needs, values, resources and organizational member desires to improve impact is created and shared in the organization.

Various definitions for the term organizational "vision" exist, but what actually are the qualities of a good vision that yields positive impact, success, and sustainable development of an organization? The authors contend that in order to achieve organizational goals within an uncertain climate, an effective vision is needed.

What do organizations need to know to plan effectively and perform their activities successfully is the focus of this paper. Previous research has identified and extended three knowledge enablers within statements: knowledge about organizational identity (OI), emerging potentiality (EP) and mutual embeddedness (ME).

A qualitative content analysis of vision statements of Forbes 2000 listed companies was conducted. This paper asks the question, "Are the three previously identified knowledge enablers regarding knowledge about organizational identity, emerging potentiality and mutual embeddedness also identifiable in a very large data set such as the Forbes-2000 company visions"?

It was determined all three knowledge enablers in the sample and the rank of companies in the Forbes 2000 list correlates not only with the occurrence of knowledge enablers, but also with the frequency of knowledge about emerging potentiality. Consequently, companies require support to create this specific knowledge enabler. This study contributes to knowledge-based vision development research and continues the ongoing discussion in the KM community.

The creation of a shared organizational vision can be seen as an instance of a knowledge creating and uses organizational learning processes that transforms personal visions and personal organizational visions through a dialectic process as indeed a shared organizational vision. During this process, knowledge about needs, values, resources and desires is created and shared in the organization.

In so doing, we summarize extant literature on developing shared visions and synthesize the literature into a process model which can be applied by academics and practitioners alike.

\section{Conclusion}

We personally welcome all returning authors, new authors, as well as virtual attendees and thank them for great participation in the virtual conference during another year of learning and professional development at HICSS-55. We look forward seeing new and ongoing research in the RFTF Minitrack.

We wish to thank each of this years' presenters for their research and willingness to share their results with us during the virtual celebration for HICSS-55. Please feel free to connect with us so we may assist you in developing a submission for next year.

Reviewers also play a key role in the review and acceptance processes of the submissions and for those willing to review, you add much to the Minitrack and hope you will again review when called upon.

As Chair of the RFTF Minitrack, I would like to say a special "thank you" to Alexander Kaiser, my CoChair for his support and kindness throughout the completion of the review process for our Minitrack. He assisted with providing additional reviewers and marketing efforts. His input throughout this year proved invaluable.

As the Knowledge Innovation and Entrepreneurial Systems Track continues to grow, we invite new 
researchers to submit applied papers that contribute to the knowledge of this exciting area, Reports from the Field. With continues emphasis on application, we encourage all practioners and theorists to contribute to the body of knowledge and contribute to many great discussions at HICSS.

We look forward seeing new research studies that contribute to application of Knowledge Management to organizations, and entrepreneurs and solopreneurs within the business and industrial community. We hope researchers will consider contributing to our mini-track, Reports from the Field next year.

\section{Chairs}

Dr. Julee Hafner (Primary Contact)

The Chicago School of Professional Psychology

325 N Wells St., Chicago, Ill 60654

Fax: +1 (321)-632-5112

Phone: +1 (321)-720-7280

E-Mail: jhhrsearch@gmail.com

Dr. Alexander Kaiser

Vienna University of Economics and Business

Phone: +43-676-3987663

E-Mail: alexander.kaiser@wu.ac.at 